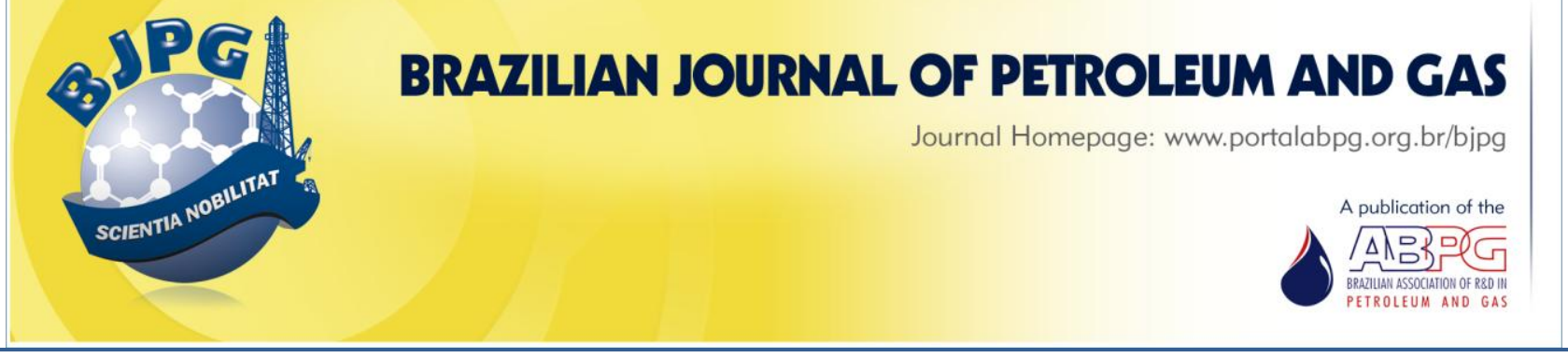

\title{
EVALUATION OF THE BEHAVIOR OF BIODEGRADABLE LUBRICANTS IN THE DIFFERENTIAL STICKING COEFFICIENT OF WATER BASED DRILLING FLUIDS
}

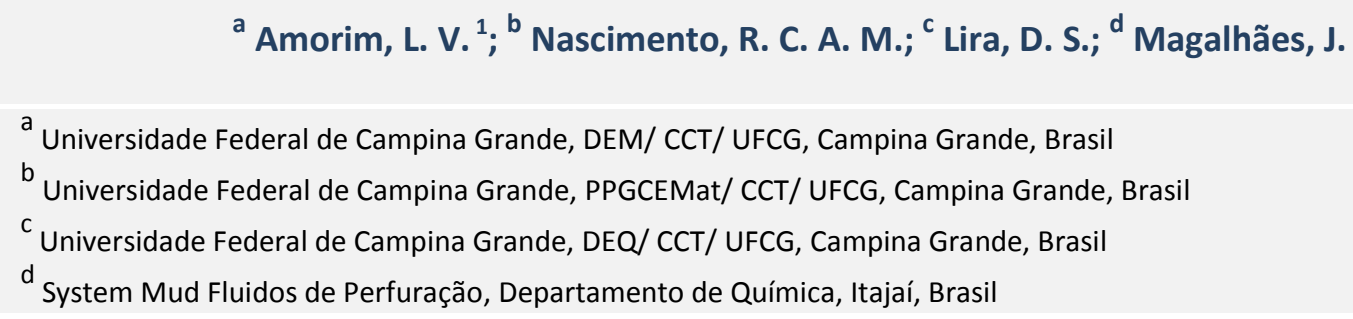

\section{ABSTRACT}

This work aims to evaluate the behavior of four samples of biodegradable lubricants in the differential sticking coefficient of aqueous drilling fluids. Eighteen formulations of fluids containing bentonite clay, lubricants and biodegradable polymers in different concentrations were studied. The experiment focused on observing the samples' rheological properties, its filtration, the cake thickness, the lubricity coefficient, and, finally, the coefficient of the differential sticking. The results showed that the polymer additives improved rheological and filtration properties significantly. Also, the findings confirmed the idea that the presence of a lubricant leads to a reduction in lubricity, LC, and affects the differential sticking coefficient, DSC, of the fluids. However, the experiment observed a small variation on the $L C$ as a result of an increase in the lubricant content. Overall, the results of the LC and the DSC of the fluids containing biodegradable lubricant additives were outstanding, being similar to the ones observed for oil-based fluids.

\section{KEYWORDS}

aqueous fluids; biodegradable lubricants; differential sticking

\footnotetext{
${ }^{1}$ To whom all correspondence should be addressed.

Address: Universidade Federal de Campina Grande, DEM/ CCT/ UFCG, Rua Aprígio Veloso, 882, CEP: 58429-140, Campina Grande, PB, Brasil

Telephone/Fax: +55 83 21011483/+55 83 21011272| E-mail: luciana@dem.ufcg.edu.br doi:10.5419/bjpg2011-0019
} 


\section{INTRODUCTION}

In petroleum engineering, drilling fluids are specially formulated to be used during perforating operations to control fluid loss and minimize formation damage. These fluids help minimize fluid invasion when perforating oil or gas bearing zones with an over-balanced fluid (Calçada et al., 2011). The drilling fluids used to help the drilling operations in oil wells must be capable of producing a cake, a thin membrane with low permeability that covers the hole's wall. The cake is formed by the deposition of clay particles on the walls while the liquid phase (water, for the waterbased fluids) of the fluid penetrates in the particles' pores. The thickness of this membrane increases when the fluid loses water to the geological formation in which it has contact with. Once a certain level of thickness is reached, the membrane waterproofs the well, preventing the loss of water by filtration (Medeiros, 2009).

The cake becomes increasingly important during drilling operations. It helps consolidating the geological formation, maintaining the stability of the well. It also reduces the loss of the filtrate by decreasing the flow of the continuous phase of the fluid into the interior of the geological formations (Darley and Gray, 1988), improving the security of the drilling.

The improper control of the cake thickness can cause several problems during the drilling. Examples of this imbalance include the occurrence of excessive filtrate invasions into the geological formation, the land sliding of the hydratable formations, and the reduction of the well's diameter. Also, the sticking of the drilling column,

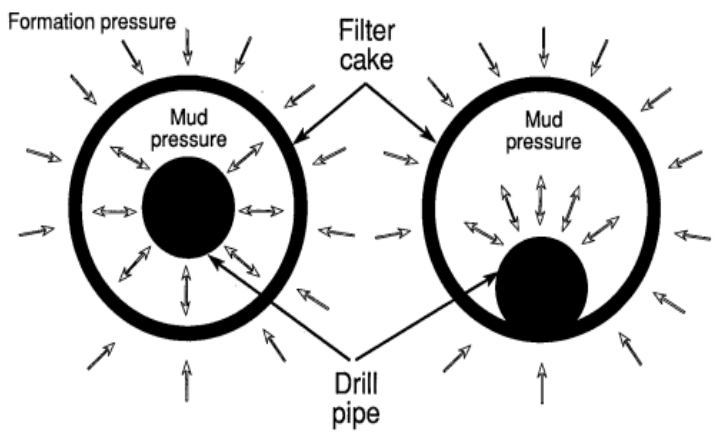

Figure 1. Differential sticking scheme. differential sticking, damage to the aquifer formations, and wrong evaluations of the investigated formations may be attributed to the inappropriate control of the cake thickness (Pereira, 2003).

The use of horizontal wells or great angle and distance wells, denominated non-conventional wells, are an alternative to the development and exploration of new fields. The utilization of nonconventional wells can also represent and option to the advanced recovery of marginal and mature fields. However, in spite of the high technology applied and the success obtained with these solutions, it is common to find during the drilling of wells the differential sticking phenomenon (Santos, 2000).

The differential sticking is caused by a differential pressure (Figure 1). It occurs when the drilling fluid column exerts excessive pressure on the cake deposited on a permeable formation (Simon, 2005). In this type of sticking, the circulation of the fluid is maintained, but it is impossible to move of rotate the tubes in any direction (Schlumberger, 2010). Generally, this occurs when there is a break for maneuvers or connections and the commands are in front of permeable formations. This phenomenon takes place especially in sandstones, where a cake forms on the walls of the well due to the filtration of drilling fluid causing the deposition of solids. The difference of pressure created in this interval along with the presence of the cake exerts a suction effect of the commands against the cake (Cardoso Júnior, 1992). The bad dimensioning of the drilling fluids and the presence of permeable formations contribute to the sticking.

The permeable rock formations are more susceptible to the differential sticking phenomenon. On those formations, the cake is accumulated during the drilling, similarly to what occurs in the directional wells, because the contact between the walls and the drill column, more specifically the bottom well assembly- BHA, is bigger (Cardoso Júnior, 1992). The diagnostic showing that differential sticking has occurred comes normally from the fact that the drilling tubes cannot be rotated or displaced either up or down, but fluid circulation is still possible. When differential sticking occurs, a significant force is required to release the drill column, regardless of 
the creation of pressure imbalances in the interior of the well. Therefore, there is still a chance that the equipment can stay several hours in operation releasing the column. In severe cases the tubes cannot be released, and the well has to be deviated or even abandoned, rendering methods to reduce the risk of differential sticking extreme importance (Bushnell-Watson and Panesar, 1991).

One of the methods used to reduce these risks entails knowing the composition and optimizing the properties of the drilling fluids. Some variables can significantly influence the differential sticking and its control guaranteeing the success of the drill. Examples of these variables include density, solid content, types of fluid, fluid formulation, filtered volume, and cake qualities that include cake thickness, resistance, and lubricity (Reid et al., 2000).

Wells drilled with fluids that have low solid content, adequate viscosity, lubricity, as well as a good filtrate, and cake control will unlikely present the differential sticking problem. Several types of materials have been used in water-based fluids to control the filtration and the cake. A list of these materials include pre-gelatinized amides, cellulose based polymers (carboximethylcellulose - CMC), and calcite.

Depending on their characteristics, such materials can develop viscosity, forming a tenuous coat and water proofing the walls of the wells, controlling the filtrate and the cake. In the event that the drilling fluid also contains bentonite clays, its particles will help adjust the formed cake consistency making the cake water proof (Reid et al., 1996). Santos (2000) found that the problems with differential sticking are generally related to the increase in cake thickness; the thicker the cake, the higher will be the differential sticking coefficient.

Other important factor in reducing the risk of differential sticking is the presence of a lubricant. The addition of a lubricant to the fluid reduces the friction between the drill column and the cake surface and, consequently, the torque necessary to restart the column movement. The sticking potential also varies according to the formulation and the type of fluid used, which can be waterbased, oil-based, or synthetic. According to Reid et al. (2000), the oil-based fluids present a lower differential sticking coefficient when compared to the water-based fluids. This finding can be explained by the lubricant characteristic of this type of fluid.

The lubricants are used in water-based fluids to make up for the necessity of lubrication during the drill. These additives consist of active-surface compounds with affinity for metallic surfaces, which are in constant contact with either the geological formations or other metallic surface (Gomes and Filho, 2005). Many studies show that the addition of certain lubricants does reduce the risk of differential sticking, in addition to reducing the force necessary to release the tubulation or a tool (Bushnell-Watson and Panesar, 1991).

According to Reid et al. (1996), the most efficient lubricants are the ones that operate through several mechanisms, depending on their chemical composition and on their dispersion state in the fluid. These efficient lubricants can coat metallic surfaces, reducing the adherence of the steel to the cake. Also, they can be incorporated to the cake promoting a better control of the fluid loss, resulting in thinner cakes, and reducing its elasticity.

The good dimensioning of the fluids in drilling oil wells, as mentioned above, can reduce differential sticking problems. Differential sticking problems are linked to non-productive rig time and represent one of the main causes of the increase in drilling costs. According to the facts presented by Santos (2000), events related to differential sticking throughout world can be responsible for up to $40 \%$ of the total cost of the well. Besides, the mechanism that probably contributes the most to the sticking of the tubes is the friction between the drill column and the walls of the hole. This friction is influenced strongly by the overbalance pressure, which occurs when the fluid's pressure is higher than the formation pressure. Consequently, the bigger the overbalance pressure is, the bigger the friction force will be (Santos, 2000). In this case, the use lubricant fluid becomes indispensible during the drilling of oil wells. Considering the exposed, this study aims to evaluate the behavior of biodegradable lubricants on the differential sticking coefficient of water-based drilling fluids. 
Table 1. Compositions of the drilling fluids.

\begin{tabular}{|c|c|c|c|c|c|c|c|c|}
\hline Fluids & $\begin{array}{c}\text { Water } \\
(\mathrm{mL})\end{array}$ & $\begin{array}{c}\text { Clay } \\
\text { (g) }\end{array}$ & $\begin{array}{l}P_{1} \\
(g)\end{array}$ & $\begin{array}{l}P_{2} \\
(g)\end{array}$ & $\begin{array}{l}\text { Lub }_{1} \\
\text { (mL) }\end{array}$ & $\begin{array}{l}\mathrm{Lub}_{2} \\
\text { (mL) }\end{array}$ & $\begin{array}{l}\mathrm{Lub}_{3} \\
(\mathrm{~mL})\end{array}$ & $\begin{array}{l}\mathrm{Lub}_{4} \\
(\mathrm{~mL})\end{array}$ \\
\hline$F_{1}$ & 500 & 12.5 & 0.08 & - & - & - & - & - \\
\hline$F_{2}$ & 500 & 12.5 & 0.08 & - & 5.0 & - & - & - \\
\hline$F_{3}$ & 500 & 12.5 & 0.08 & - & 10.0 & - & - & - \\
\hline$F_{4}$ & 500 & 12.5 & 0.08 & - & - & 5.0 & - & - \\
\hline$F_{5}$ & 500 & 12.5 & 0.08 & - & - & 10.0 & - & - \\
\hline$F_{6}$ & 500 & 12.5 & 0.08 & - & - & - & 5.0 & - \\
\hline$F_{7}$ & 500 & 12.5 & 0.08 & - & - & - & 10.0 & - \\
\hline$F_{8}$ & 500 & 12.5 & 0.08 & - & - & - & - & 5.0 \\
\hline$F_{9}$ & 500 & 12.5 & 0.08 & - & - & - & - & 10.0 \\
\hline$F_{10}$ & 500 & 12.5 & - & 0.08 & - & - & - & - \\
\hline$F_{11}$ & 500 & 12.5 & - & 0.08 & 5.0 & - & - & - \\
\hline$F_{12}$ & 500 & 12.5 & - & 0.08 & 10.0 & - & - & - \\
\hline$F_{13}$ & 500 & 12.5 & - & 0.08 & - & 5.0 & - & - \\
\hline$F_{14}$ & 500 & 12.5 & - & 0.08 & - & 10.0 & - & - \\
\hline$F_{15}$ & 500 & 12.5 & - & 0.08 & - & - & 5.0 & - \\
\hline$F_{16}$ & 500 & 12.5 & - & 0.08 & - & - & 10.0 & - \\
\hline$F_{17}$ & 500 & 12.5 & - & 0.08 & - & - & - & 5.0 \\
\hline$F_{18}$ & 500 & 12.5 & - & 0.08 & - & - & - & 10.0 \\
\hline
\end{tabular}

\section{MATERIALS AND METHODS}

\subsection{Drilling fluids}

The drilling fluids were prepared using (i) a sample of sodium bentonite clay, widely used in the oil well drilling industry, from the State of Paraíba, Brazil; (ii) two polymeric additives with different functions, one being a viscosity agent (P1) and the other a filtrate reducer (P2); and (iii) four types of lubricants, named Lub1, Lub2, Lub3, and Lub4, studied in different concentrations. The compositions of the fluids are presented in Table 1.

\subsection{Methods}

\subsubsection{Preparation of drilling fluids}

The drilling fluids were prepared following the rule N-2604 from PETROBRAS (1998a). The clay and the polymers were mixed with deionized water and maintained under mixing at a speed of 17000 rpm for 20 minutes in a Hamilton Beach mechanical mixer, model 936. Then, the fluids were left at rest for a 24 hour period in a closed container. After the rest, the fluids, including those with lubricant additives, were mixed for 5 minutes, and, then, the lubricant was added. The mixing was done manually until total dissolution.

\subsubsection{Rheology}

After the rest, a rheological study was made, using a Fann 35A viscometer, in order to obtain the viscosity curves, the apparent and plastic viscosities, and the yield strength. Initially, the fluids were submitted to an agitation of $600 \mathrm{rpm}$ during 2 minutes, and the reading was done on the viscometer $\left(L_{600}\right)$. Then, the speed was changed to $300 \mathrm{rpm}$, and the reading was done after 15 seconds $\left(L_{300}\right)$. Following, the fluid was submitted to a speed of $200 \mathrm{rpm}$ and the measure was done after the stabilization of the equipment's marker $\left(L_{200}\right)$. At the speeds of $100 \mathrm{rpm}\left(L_{100}\right), 6 \mathrm{rpm}\left(L_{6}\right)$, and $3 \mathrm{rpm}\left(L_{3}\right)$ it was used the same procedure described above to obtain the reading at $200 \mathrm{rpm}$.

The values of apparent viscosity (AV), plastic viscosity $(P V)$, and yield strength $(Y S)$ were obtained from equations 1,2 , and 3 . The viscosity curves, viscosity versus shear rate, of the drilling fluids were obtained using a mathematical treatment and the Fann 35A viscometer's parameters.

$$
\begin{aligned}
& A V=\frac{L_{600}}{2}(c P) \\
& P V=L_{600}-L_{300}(c P)
\end{aligned}
$$




$$
Y S=L_{300}-P V\left(N / m^{2}\right)
$$

\subsubsection{Lubricity}

The lubricity coefficient of the fluids was determined using an OFITE, EP-Lubricity Tester, according to the methodology recommended by the manufacturer's manual. Thus, after mixing the fluid for $5 \mathrm{~min}$ in a Hamilton Beach mechanical mixer, model 936, at a $17000 \mathrm{rpm}$ speed, it was transferred to the equipment's container. The initial torque was zero and the speed was of 60 $\mathrm{rpm}$. Then, slowly, it was applied a $150 \mathrm{lbf} /$ in force, equal to a pressure of 34.5 to $69.0 \mathrm{kPa}$, during 5 minutes, followed by the reading of the torque exerted by the fluid. With the torque obtained in a test performed with water, the correction factor (CF) was calculated according to the equation 4, and the lubricity coefficient $(L C)$ according to the equation 5.

$$
\begin{aligned}
& C F=\frac{34.0}{\text { Reading }_{\text {water }}} \\
& L C=\frac{C F \times \operatorname{Re} \text { ading }_{\text {fluid }}}{100}
\end{aligned}
$$

\subsubsection{Filtered volume}

The filtered volume of the fluids was obtained in the API filter-press by applying pressure on the order of $100 \mathrm{psi}, 7.0 \mathrm{kgf} / \mathrm{cm}^{2}$. After 30 minutes, the filtered volume was collected and measured in $\mathrm{mL}$ according to the rule $\mathrm{N}-2604$ from PETROBRAS (1998a).

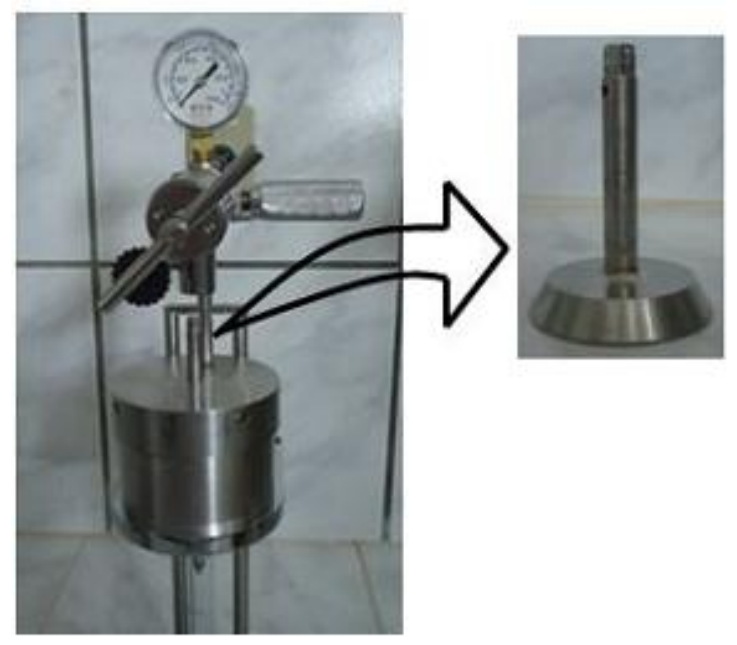

Figure 2. Differential sticking tester Fann and flat plate.

\subsubsection{Cake thickness}

To determine the cake thickness, it was used a methodology developed by Farias (2005). Initially, it was collected the filter paper with the cake formed during the filtered volume experiment, and it was washed three times at a constant flow of approximately $110 \mathrm{~L} / \mathrm{h}$ at a distance near $7.0 \mathrm{~cm}$ from the flow controller, with a diameter of 15.0 $\mathrm{mm}$ and an angle of attack of about $45^{\circ}$.

After the washing, the filter paper was put in between two glass slides, which had the same diameter of the paper, and it was submitted to a pressure of $277.6 \mathrm{~N} / \mathrm{m}^{2}$ for 2 minutes. Following, the slides with the filter paper and the cake were put in an extensometer where the measures of the thickness of the cake were done. At that time, 5 readings of thickness in different spots of the cake were taken. After the attainment of the measures, the arithmetical average of the five readings was calculated.

\subsubsection{Differential sticking}

The differential sticking coefficient was obtained in a Fann Differential Sticking Tester equipment making use of the flat plate, according to Figure 2. The methodology used was suggested by the manufacturer, and consisted of transferring the fluid to the equipment's cell, applying a pressure on the order of $477.5 \mathrm{psi}(3292 \mathrm{kPa})$, and waiting $10 \mathrm{~min}$ for the occurrence of the formation of cake.

After the formation of the cake, the flat torque plate was lowered to allow an interaction between the cake and plate surfaces, simulating a differential sticking situation. After waiting for 10 more minutes, 6 measures of torque were taken with help of a torque meter. Having the values of the torque measures, the differential sticking coefficient $(D S C)$ could be obtained according to the equation 6 .

$$
D S C=\frac{T_{m}}{100}
$$

where, $T_{m}$ is the arithmetical average of the torque measures. 

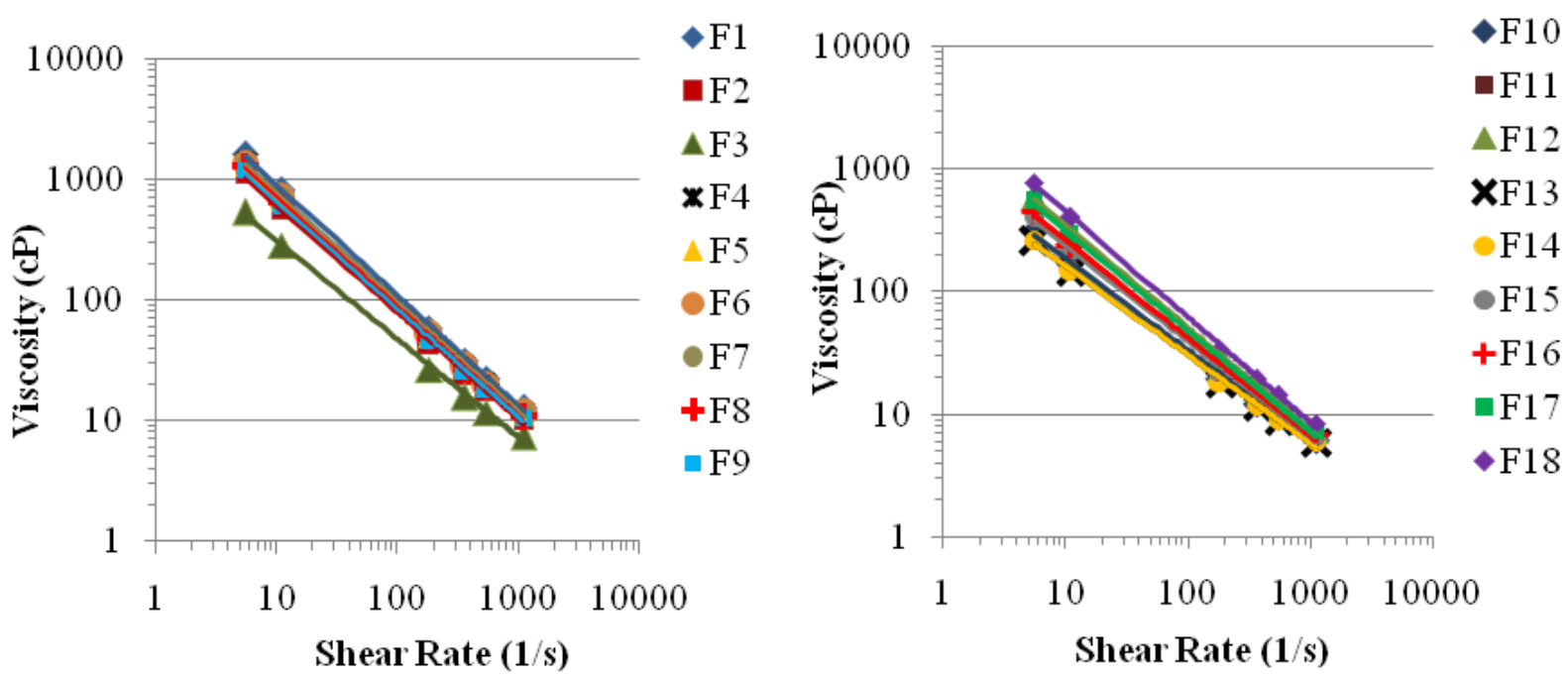

Figure 3. Viscosity curves of the clay and water fluids (a) $F_{1}$ to $F_{9}$ (with polymer $P 1$ ) and (b) $F_{10}$ to $F_{18}$ (with polymer $\mathrm{P} 2)$.

\section{RESULTS AND DISCUSSION}

To evaluate the behavior of the lubricants on the differential sticking coefficient of drilling fluids it is also important to do an investigation of rheological, filtration, and lubricity properties. These investigations will determine if the developed fluid attends the required specifications for an adequate drilling (Nascimento, 2011).

Figure 3 presents the viscosity curves of the clay and water fluids named F1 to F18. According to Figure 3 , it can be observed that at low shear rates the fluid has higher viscosity. When the shear rate increases, the viscosity tends to decrease, presenting the behavior of pseudoplastic fluids with yield strength. This behavior results from the presence of polymers in the studied fluids, according to studies done by Medeiros (2009). It can also be observed that the addition of lubricants does not alter this behavior, see fluids F2 to F9 and F11 to F18.

In Table 2 are presented the values of the rheological properties, apparent viscosity (AV), plastic viscosity $(P V)$, and yield strength (YS); and the filtration properties filtered volume $(F V)$, and cake thickness (CT) of the studied fluids.

Table 2. Rheological and filtration properties of the studied drilling fluids.

\begin{tabular}{cccccc}
\hline Fluids & $\boldsymbol{A} \boldsymbol{V}(\mathbf{c P})$ & $\boldsymbol{P} \boldsymbol{V}(\mathbf{c P})$ & $\boldsymbol{Y S}\left(\mathbf{N} / \mathbf{m}^{\mathbf{2}}\right)$ & $\boldsymbol{F} \boldsymbol{V}(\mathbf{m L})$ & $\boldsymbol{C} \boldsymbol{T}(\mathbf{m m})$ \\
\hline $\mathrm{F}_{1}$ & 19.3 & 6.5 & 25.5 & 14.0 & 1.172 \\
$\mathrm{~F}_{2}$ & 16.5 & 6.0 & 21.0 & 14.0 & 1.181 \\
$\mathrm{~F}_{3}$ & 14.0 & 6.0 & 13.0 & 12.0 & 0.876 \\
$\mathrm{~F}_{4}$ & 19.0 & 8.0 & 22.5 & 14.0 & 1.157 \\
$\mathrm{~F}_{5}$ & 15.8 & 10.0 & 11.5 & 12.3 & 1.378 \\
$\mathrm{~F}_{6}$ & 18.0 & 6.0 & 24.0 & 14.8 & 1.194 \\
$\mathrm{~F}_{7}$ & 17.0 & 8.0 & 18.0 & 13.0 & 1.038 \\
$\mathrm{~F}_{8}$ & 19.3 & 8.5 & 21.5 & 12.2 & 1.184 \\
$\mathrm{~F}_{9}$ & 19.5 & 9.5 & 20.5 & 12.3 & 0.886 \\
$\mathrm{~F}_{10}$ & 15.0 & 8.5 & 13.0 & 12.0 & 1.470 \\
$\mathrm{~F}_{11}$ & 13.5 & 7.0 & 13.0 & 12.5 & 1.053 \\
$\mathrm{~F}_{12}$ & 15.3 & 8.0 & 14.5 & 10.2 & 0.868 \\
$\mathrm{~F}_{13}$ & 15.8 & 10.0 & 11.5 & 12.0 & 1417 \\
$\mathrm{~F}_{14}$ & 19.0 & 6.5 & 24.0 & 12.3 & 0.914 \\
$\mathrm{~F}_{15}$ & 15.3 & 9.5 & 11.5 & 13.3 & 1.153 \\
$\mathrm{~F}_{16}$ & 15.0 & 8.0 & 12.0 & 11.4 & 0.927 \\
$\mathrm{~F}_{17}$ & 18.5 & 10.5 & 16.0 & 9.2 & 1.324 \\
$\mathrm{~F}_{18}$ & 20.0 & 10.0 & 20.0 & 10.2 & 1.264 \\
\hline
\end{tabular}


The properties of the clay and water fluids are influenced by the type and content of clay. Fluids which have low contents of clay, like the ones with $2.5 \%$, do not present adequate properties. Therefore, the addition of polymer additives is indispensable to improve the efficiency and facilitate the drilling in the initial phases of a well. This possibility is associated to the fact that the clay particles have charges that allow the interaction with the polymer molecules present in the fluids. The variation of the viscosity can be explained by the electrostatic and mass interactions. According to Amorim et al. (2005), these interactions promote the formation of hard reticulates, which retain the water molecules reducing the quantity of free water in the system. These reticulates increase the viscosity, reduce VF, and present a considerable cake thickness, which, according to Isambourg et al. (1999), has great influence in the differential sticking.

The results exposed in Table 2 show that the presence of polymer additives improved significantly the rheological properties of the fluids, being the fluids $\mathrm{F} 1$ to $\mathrm{F} 9$, with polymer $\mathrm{P} 1$ additive, the ones which presented the highest apparent viscosity values, while the fluids F10 to F18, with polymer P2 additive, presented the lowest filtered volume values. This behavior is characteristic of the different polymers used; the polymer P1 had the main function to confer viscosity to the fluid, while the polymer P2 acted on reducing the loss by filtration. The fluids presented values of plastic viscosity that ranged between 6.0 and $10.0 \mathrm{cP}$. The values of $Y S$ ranged between $11.5 \mathrm{~N} / \mathrm{m}^{2}$, for the $\mathrm{F} 5$, $\mathrm{F} 13, \mathrm{~F} 15$, and $25.5 \mathrm{~N} / \mathrm{m}^{2}$, for fluid $\mathrm{F} 1$.

Even though the lubricant was added to guarantee excellent lubricity results, it is important to observe that its addition altered, although in a soft way, the rheological properties of the fluids. The studied lubricants had different chemical compositions, therefore, different behaviors in aqueous ambient.

The Lub1 is a chemically modified vegetal oilbased lubricant to be soluble in water. When added to fluids that contain bentonite clay, it acts as a dispersant, blinding the charges present on the surfaces of the clay particles, reducing the values of $A V, P V, Y S, F V$ and $C T$ (Medeiros et al., 2008). This mixture allows an interaction between the lubricant molecules and the positive charges present on the surface of the clay particles. This interaction, on the other hand, turns difficult the connections between clay particles and, therefore, the formation of tridimensional structures. As result, there is a reduction in filtration and rheological properties.

The Lub2 is an acid ester of a short chain and ethanol, insoluble in water, without charges, only dipoles. However, in the presence of water, it forms micelles that make the contact between the clay particles difficult due to spatial obstruction. The micelles found between the clay particles prevent the occurrence of any chemical interactions. As result, there is a dispersion effect that leads to a reduction in filtration and rheological properties of the fluids.

The lubricants Lub3 and Lub4 are mixtures of greases extracted from plants, the vegetable oils. They are esters that are insoluble in water and that form droplets which disperse in aqueous ambient. These droplets are extremely small, giving the impression of being a soluble product. The micro droplets are chemically stabilized by the other components of the fluid and have a dispersant action.

According to the specifications from PETROBRAS (1998b) for clay's qualifications, the drilling fluids must present filtered volume values lower than $18 \mathrm{~mL}$ to fit in the type I classification. It can be observed in Table 2 that all the studied fluids are within the specifications. For the fluids with $\mathrm{P} 1$ additive, the viscosity agent polymer, the increase in the concentration of the lubricant from $1.0 \%$ to $2.0 \%$ provided a bigger reduction of $F V$, while for the fluids with $\mathrm{P} 2$, the increase in the concentration of Lub4 occasioned an increase in the $F V$. The reduction of the $F V$ values was justified by the chemical alteration promoted by the lubricants and the polymers present in the fluids. The lubricants act on the cake blinding the clay particles, making it difficult for the free water to flow.

Still according to Table 2, it was verified that the fluids that presented bigger cake thickness were the fluids F1, F2, F6, F5, F10, F13, F17, and F18. According to Ferraz (1977), the cake is formed by the deposition of the clay particles on the walls of the hole during the loss of water to the formations. The bigger the filtered volume is, the thicker the cake will be. According to Reid et al. (1996), the 

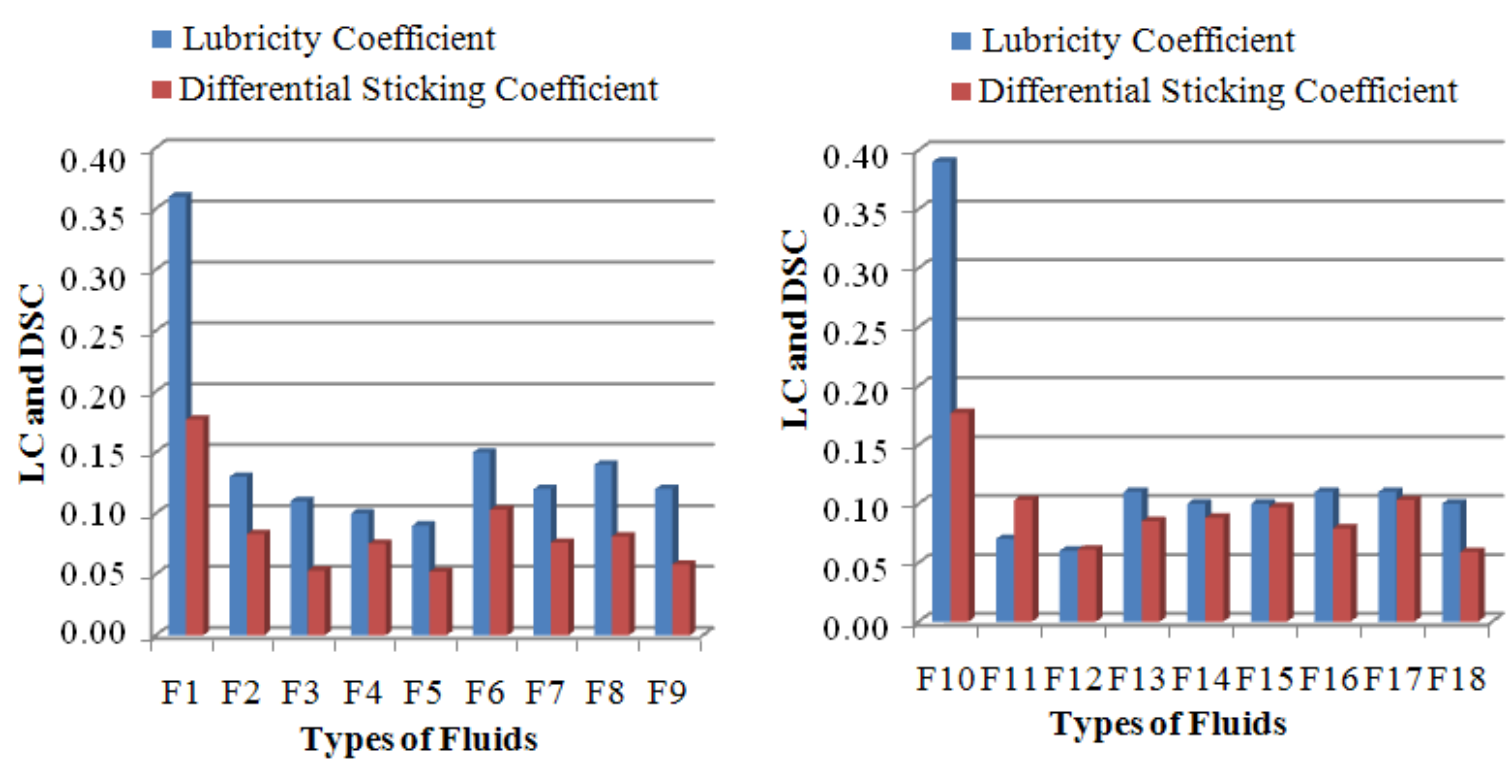

Figure 4. Lubricity (LC) and differential sticking (DSC) coefficients of the drilling fluids (a) with polymer P1 and (b) with polymer P2.

cakes' properties, thickness, resistance to shear, and lubricity, are the most important parameters in the reduction of differential sticking. However, these properties are influenced by a combination of variables that includes high and low solid contents in the fluid, type of fluid, specific composition of the fluid, and filtered volume. A thick cake reduces effectively the diameter of the hole and increases the contact area between the drill tube and the cake, contributing to an increase in the risk of having stuck tubes. The lubricity $(L C)$ and the differential sticking (DSC) coefficients of the studied fluids are illustrated in Figure 4.

According to the literature, fluids that have adequate lubricity must present a $L C$ of the order of 0.1 , value commonly found in oil-based drilling fluids, or in fluids with lubricant additives (Darley and Gray, 1988). Although the fluids prepared with diesel oil present better lubricity coefficients than the water-based fluids, they are no longer in use due to the negative environmental impact that they can cause. In substitution to the diesel fluids, synthetic fluids have been used since they have proven to cause less damage to the environment. However, the high costs of involved in the production of synthetic fluids limit the use (Schaffel, 2002).

In Figure 4, it was observed that the fluids prepared only with clay and polymers, F1 and F10, presented elevated lubricity and differential sticking coefficients. The addition of the lubricants achieved the reduction expected in the values of $L C$ and DSC, F2 to F9 and F11 to F18, since that the lubricant formed a protection coating between the two surfaces, reducing the friction and the waste. Moreover, the lubricants helped controlling the temperature control, promoting cleaning and protecting the equipment from the corrosion due to the oxidation process. It also acted as a force and movement transmission agent (Gomes and Filho, 2005).

Within the fluids with lubricant additives, F4, F5, $F 11, F 12, F 14, F 15$, and F18 presented values of $L C$ lower or equal to 0.1 . Among the biodegradable lubricants that were studied, the ones denominated as Lub1 and Lub2 were the ones that presented the best results, being considered excellent lubricants. The fluids which contained Lub1 presented the best results when combined with $\mathrm{P} 2$ additive, considering that the $\mathrm{LC}$ reduced from 0.39 (F10) to 0.07 (F11), and 0.06 (F12). Among the fluids that had Lub2, the ones that had best results were the fluids F4 (0.10) and F5 (0.09), with $\mathrm{P} 1$ additive.

These results are justified by the fact that Lub1, as mentioned before, is lubricant that has a vegetable oil base that is soluble in water and has dipoles and charges. So, it forms a film over the surface that is capable of promoting interactions stronger than the ones attributed to common oils. 
The adherence of the lubricant to the cake's clay particles permitted a lower friction condition between the constituent solids and, consequently, better values of LC were obtained. Because Lub2 is a dispersible lubricant, but not soluble, it promoted a cakeless lubricant, and the reduction of the friction was attributed to the presence of the micelles between the disperse clay particles.

The $L C$ results obtained are extremely important in light of the environmental restrictions over the drilling fluids. Nowadays there is demand for the development of new nontoxic formulations. According to Argilier and Audibert (1996), esterbased lubricants are environmentally correct, totally biodegradable and nontoxic.

When analyzing the differential sticking coefficient, a similar behavior was observed. The presence of a lubricant and an increase in its concentration reduced the values of DSC. The analysis of the experiment's results shows that Lub2 was the most efficient lubricant.

According to Reid et al. (1996), the lubricants, depending on their dispersion state in the fluids, act by three possible mechanisms: (i) in the first one, the lubricants can coat the metallic surfaces reducing the adherence between the drill tube and the cake; (ii) in the second one, can be incorporated to the cake, providing a better control of the filtered volume, resulting in thinner cakes; or, (iii) in the third one, can be incorporated to the cake reducing its plasticity. Probably, the lubricants form a coat on the surface of the flat plate, reducing the friction between the cake and the surface of the flat plate, making it easy to slide on the cake. So, in consequence, there is the reduction of the force necessary to release the equipment stuck to the cake.

According to Bushnell-Watson and Panesar (1991), in aqueous fluids as well as in non-aqueous fluids, the use of a lubricant affects significantly the way in which the tubes are released. In the absence of a lubricant, the tubes are released in the cake/formation interface, while in the presence of a lubricant the tubes are released in the tube/cake interface, reducing the risks during the drilling.

The $D S C^{\prime}$ 's of the fluids without lubricants (F1 and F10) presented values near 0.17. After the addition of the lubricant, these values were reduced to 0.052 (F5), and 0.053 (F3). The concentration of $1 \%$ lubricant was enough to guarantee the reduction of the risk of occurring drill string sticking. However, it is extremely important to note, that in all the fluids, except for $\mathrm{F} 14$, the increase in the concentration to $2.0 \%$ reduced even more the $D S C$. With this, it is possible to suggest that the increase of the concentration of the lubricant will reduce the risks of having differentially stuck tubes.

The fluid with the lowest DSC was F5, with Lub2 additive. Lub2 is an additive that is considered environmentally correct, biodegradable and nontoxic. Since Lub2 does not have any charges, and is insoluble in water, it formed micelles in the fluid and, when it got in contact with metallic surfaces, it detached itself, adhering to the equipment's surfaces, lubricating them. Differently, the action mechanism of Lub1, Lub3, and Lub4 took place between the clay particles and the equipment's surface.

Among aqueous and non-aqueous types of drilling fluids, the water-based presented the lowest damages to the environment. However, in drills that involve deep depths, these still do not meet all of the technical requirements needed to perform a good drill operation, such as the lubricating capacity regulations (Argillier and Audibert, 1996). By the additive technique it is possible to adequate the properties of the fluids and use them in deeper wells.

Based on these results, it is suggested that a direct correlation between lubricity and differential sticking lower the values of $L C$ and result in lower values of DSC. The lubricity is important because the fluids with this property tend to reduce the torque and drag presents during the drill operations, besides reducing the bit balling and the subsequent problems like the reduction of the penetration rate, very common in the drilling of rocks which contain intercalations of plastic clays and shale.

\section{CONCLUSIONS}

According to the obtained results, it was possible to conclude that: 
- It is essential to have the presence of polymeric additives in the clay and waterbased fluids with low clay contents to guarantee adequate rheological (AV, PV and YS), and filtration (FV and $\mathrm{CT}$ ) properties of the drilling fluids;

- The addition of lubricants did not compromise rheological and filtration behaviors of the drilling fluids;

- The polymeric additives, viscosity agent or filtrate reducer, do not alter the differential sticking coefficient;

- The presence of biodegradable lubricants reduced the lubricity coefficient of the fluids, as well as their differential sticking coefficient;

- The increase in the lubricant concentration did not present significant improvements in the lubricity coefficient, being the concentration of $1.0 \%$ enough to guarantee a good performance of the fluids;

- Increasing contents of lubricants in the fluids tend to reduce the differential sticking coefficient; and

- The fluid with $2.0 \%$ of Lub2 (F5) presented the lowest and, therefore, the best differential sticking coefficient.

In summary, it was concluded that the use of biodegradable lubricant reduces in a significant way the differential sticking coefficient of the clay and water fluids, reducing the risks of differential sticking. This result is crucial for the oil industry, since the environmental restrictions are becoming progressively more rigorous. It is important to emphasize that the lubricants evaluated in this work are environmentally correct and biodegradable, presenting enormous environmental advantages.

\section{ACKNOWLEDGEMENTS}

The authors of this work would like to thank the Agência Nacional do Petróleo- ANP, the PRH-25, and the Conselho Nacional de Desenvolvimento Científico e Tecnológico - CNPq (Process No479214/2007-7) for the financial support. They would also like to show gratitude to Company Bentonit União Nordeste Ltda- BUN for providing the bentonite clay, to Company System Mud Indústria e Comércio Ltda. for providing the additives and support to this project, and to LABDES for the use of their physical facilities.

\section{REFERENCES}

Amorim, L. V.; Gomes, C. M.; Silva, F. L. H.; Lira, H. L.; Ferreira, H. C. Estudo reológico de fluidos de perfuração à base de água: influência do teor de sólidos, velocidade e tempo de agitação. Águas Subterrâneas. v.19, n. 1, p. 75-85, 2005.

Argillier, J.F.; Audibert, A. Development of a New Non-Polluting Ester Based Lubricant for Water Based Muds: Laboratory and Field Tests Results, Institut Francais du Petrole \& Janssen, M. \& Demoulin, A., Fina Research S.A., 1996.

Bushnell-Watson, Y.M.; Panesar, S.S. Mechanisms of differential sticking and a simple well site test for monitoring and optimizing drilling mud properties, SPE 22549, 1991.

Calçada, L. A.; Scheid, C.M.; Araújo, C. A. O.; Waldmann, A.T. A.; Martins, A. L. Analysis of dynamic and static filtration and determination of mud cake parameters. Brazilian Journal of Petroleum and Gas. v.5, n.3, p. 159-170, 2011. http://dx.doi.org/10.5419/bjpg2011-0016

Cardoso Júnior, J. V. L. Diagnóstico de problemas em poços direcionais durante as manobras. Masters Dissertation in Petroleum Engineering. Centro de Ciências e Tecnologia. Universidade Estadual de Campinas - UNICAMP. Campinas, SP, 1992. (in Portuguese)

Darley, H.C.H., Gray, G.R. Composition and properties of drilling and completion fluids, Fifth Edition, Gulf Publishing Company, Houston, Texas, 1988. 
Farias, K. V. Influência do umectante aniônico na reologia e espessura de reboco de fluidos hidroargilosos. Masters Dissertation, CCT, UFCG, Campina Grande, PB, Brasil, 2005. (in Portuguese)

Ferraz, A.I. Manual de engenharia dos fluidos de perfuração, Divisão Magcobar Grupo Oilfield Products Dresser Industries, 1977. (in Portuguese)

Gomes, H.O.; Filho, J.F.O. Metodologia de avaliação da lubricidade de óleo diesel, In: Encontro para a Qualidade de Laboratórios, São Paulo, June 2005. (in Portuguese)

Isambourg, P.; Ottesen, S.; Benaissa, S; Marti, J. Down-hole simulation cell for measurement of lubricity and differential pressure sticking. SPE/IADC 52816, March 1999.

Medeiros, R.C.A. Estudo do coeficiente de lubricidade de fluidos de perfuração à base de água, Graduation Monograph in Materials Engineering, CCT/UFCG, Campina Grande, PB, Brazil, 2009. (in Portuguese)

Medeiros, R. C. A.; Amorim, L. V.; Santana, L. N. L. Avaliação de aditivos lubrificantes em fluidos aquosos para perfuração de poços de petróleo, Revista Eletrônica de Materiais e ProcessosREMAP, v.3.3, p. 56-64, 2008. (in Portuguese)

Nascimento, R. C. A. M. Estudo do desempenho de fluidos aquosos sob condições de prisão diferencial. Masters Dissertation, CCT, UFCG, Campina Grande, PB, Brasil, 2011. (in Portuguese)

Pereira, E. Uso de Inibidores de Argilas como Solução de Problemas em Sondagem, Avaliable at: www.systemmud.com.br. Accessed on: June 2003.

PETROBRAS Argila Aditivada para Fluido de Perfuração à Base de Água na Exploração e Produção de Petróleo, Method N -2605, 1998a. (in Portuguese)
PETROBRAS Argila Aditivada para Fluido de Perfuração à Base de Água na Exploração e Produção de Petróleo, Specification N -2604, 1998b. (in Portuguese)

Reid, P.I.; Meeten, G.H.; Way, P.W.; Clark, P.; Chambers, B.D.; Gilmour, A.; Sanders, M. W. Differential-sticking mechanisms and a simple wellsite test for monitoring and optimizing drilling mud properties, SPE 64114, SPE Drilling \& Completion. June 2000.

Reid, P.I.; Meeten, G.H.; Way, P.W. Mechanisms of differential sticking and a simple well site test for monitoring and optimizing drilling mud properties, IADC/SPE 35100, 1996.

Santos, H. Differential stuck pipe: early diagnostics and solution, SPE/IADC 59127, 2000.

Schaffel, S. B. A questão ambiental na etapa de perfuração de poços marítimos de óleo e gás no brasil. Dissertation (Masters in Ciências em Planejamento Energético), COPPE, Universidade Federal do Rio de Janeiro- UFRJ, Rio de Janeiro, RJ. 2002. (in Portuguese)

SCHLUMBERGER. Oilfield Glossary. Available at: http://www.glossary.oilfield.slb.com/Display.cfm?Term= differential 20sticking. Accessed on: May 2010.

Simon, K.; Gaurina-Medimurec, N.; Pasic, B. Drilling fluids differential sticking tendency. Rudarsko-geološko-naftnizbornik, UDC 622.244.442, v. 17, p. 31-35, 2005. 